\title{
Pathological features of Breast Cancer seen in Northwestern Tanzania: a nine years retrospective study
}

\author{
Peter F Rambau ${ }^{1 *}$, Philipo L Chalya ${ }^{2}$, Mange M Manyama ${ }^{3}$ and Kahima J Jackson ${ }^{4}$
}

\begin{abstract}
Background: Breast cancer is more common in Western Countries compared to African populations. However in African population, it appears that the disease tends to be more aggressive and occurring at a relatively young age at the time of presentation. The aim of this study was to describe the trend of Breast Cancer in Northwestern Tanzania.

Methods: This was a retrospective study which involved all cases of breast cancer diagnosed histologically at Bugando Medical Center from 2002 to 2010. Histological results and slides were retrieved from the records in the Pathology department, clinical information and demographic data for patients were retrieved from surgical wards and department of medical records. Histology slides were re-evaluated for the histological type, grade (By modified Bloom-Richardson score), and presence of necrosis and skin involvement. Data was entered and analyzed by SPSS computer software version 15 .
\end{abstract}

Findings: There were 328 patients histologically confirmed to have breast cancer, the mean age at diagnosis was 48.7 years (+/- 13.1). About half of the patients (52.4\%) were below 46 years of age, and this group of patients had significantly higher tendency for lymph node metastasis $(p=0.012)$. The tumor size ranged from $1 \mathrm{~cm}$ to $18 \mathrm{~cm}$ in diameter with average (mean) of $5.5 \mathrm{~cm}(+/-2.5)$, and median size of $6 \mathrm{~cm}$. Size of the tumor (above $6 \mathrm{~cm}$ in diameter) and presence of necrosis within the tumor was significantly associated with high rate of lymph node metastasis $(p=0.000)$. Of all patients, $64 \%$ were at clinical stage III (specifically IIIB) and $70.4 \%$ had lymph node metastasis at the time of diagnosis. Only $4.3 \%$ of the patients were in clinical stage I at the time of diagnosis. Majority of the patients had invasive ductal carcinoma (91.5\%) followed by mucinous carcinoma (5.2\%), Invasive lobular carcinoma (3\%) and in situ ductal carcinoma (0.3\%). In all patients, 185 (56.4\%) had tumor with histological grade 3.

Conclusion: Breast cancer in this region show a trend towards relative young age at diagnosis with advanced stage at diagnosis and high rate of lymph node metastasis. Poor Referral system, lack of screening programs and natural aggressive biological behavior of tumor may contribute to advanced disease at the time of diagnosis.

Keywords: Breast Cancer, North Western Tanzania

\section{Background}

Breast cancer is a significant cause of mortality worldwide, with a prevalence that is estimated to be $1,000,000$ annually[1]. In African women, the diagnosis is often made between 35 and 45 years of age. This is fifteen years earlier than women in Europe and North America. One study showed the mean age of diagnosis in black

\footnotetext{
* Correspondence: prambau@bugando.ac.tz

'Department of Pathology Weill Bugando University College of Health

Sciences, Box 1464 Mwanza, (Bugando Street) Postal code +255, Tanzania

Full list of author information is available at the end of the article
}

patient was 57.6 years with large tumor size compared to 62.6 years in white patients. The overall incidence was lower in black women although for patients younger than 40 years the incidence was higher by $20 \%$ in black women[2]. The estimated age standardized rates for breast cancer incidence in sub-Saharan Africa range from 15 to 53 per 100, 000 women, which is lower than what is seen in Western countries[3]. The mortality rate tends to be high among women in sub-Saharan Africa as tumors tend to be very aggressive with short periods of time between the onset of symptoms and diagnosis[4].

\section{Biomed Central}


In Tanzania, breast cancer accounted for $8.1 \%$ of all female cancers in years 1974-1987, and most of the patients were under 30 years of age[5]. A study done in Dar-es-Salaam on 50 patients showed that most patients presented with advanced stage with no single patient in stage I, and the the majority were in stage IIIB[6]. In other parts of the world older women are at high risk, where approximately $77 \%$ of the breast cancer occurs in women over 50 years[7], but this trend is somehow different in Africans where the disease is common at young age[3]. In sub Saharan Africa, the disease is seen commonly in women below 30 years of age[8].

Few studies have shown that breast cancer in Africans tends to present at a young age with advanced aggressive disease with a poor prognosis compared to Western white females $[4,9,10]$. Furthermore, breast cancer in Africa shows the trend of rapid increase[11].

Several factors have been implicated in the prognosis of the patients with breast cancer. Age has been shown to be an important factor in the prognosis of breast cancer, where by disease presentation at young age has shown a worse prognosis than in older age[12]. This has been explained by the fact that cancer at young age tends to be more aggressive and biological behavior could be different. In Africans, breast cancer tends to present at young age and this could be a reasons for bad prognosis in these patients [4,8-10].

The clinical stage of the disease at presentation is important for the outcome of the patient with breast cancer. In most African patients, especially at young age, the disease present at an advanced stage [3,8]. This can be explained by delay in seeking medical services, poor medical service with no screening programs for breast cancer. The staging of the patient in conjunction with histological grade can be used to determine the prognosis of the patient. Whereas stage I disease has about $96 \% 5$-year survival, this can be as low as 18\% 5year survival rate in stage IV. By using histological grade alone, histological grade I has about 93\% 5-year survival. Stage I disease with histological grade I has shown a 99\% 5-year survival compared to only $13 \% 5$-year survival in stage IV with histological grade III[13-15]. Histological grade used is that described by Bloom \& Richardson[16].

One less common histological type of breast cancer called centrally necrotizing carcinoma of the breast has shown to be more aggressive by having early metastasis and rapid clinical progression and it was found to be good for determining prognosis in pre-menopausal women $[17,18]$. This study was therefore, carried to describe clinical and pathological features of patients with breast cancer in this region and compare the trends with other regions.

\section{Methods}

This was a retrospective study of histologically confirmed cases of breast cancer seen at the department of Pathology of Bugando Medical Centre (BMC) over a period of 9-years between January 2002 and September 2010. BMC is a consultant, tertiary care and teaching hospital for the Weill-Bugando University Collage of Health Sciences (WBHCHS) with a bed capacity of 870 . Subjects of this study included all histologically confirmed breast cancer made during the period of 2002 to 2010. Data was retrieved from the records in the Pathology department. Histology slides were re-evaluated for histological type; and grade was established by Modified Bloom-Richardson score system which scores for tubular formation, nuclear pleomorphism and mitotic rate within tumor cells. Other tumor morphological features like presence of necrosis, and involvement of the skin was evaluated. The clinical stage of the disease was assigned to each patient by using TNM (AJCC cancer staging manual); this is a staging system which is expression of anatomical extent of disease based on extent of primary tumor $(\mathrm{T})$, absence or presence of and extent of regional lymph node metastasis $(\mathrm{N})$ and absence or presence of distant metastasis. The clinical information and demographic information was obtained from Patients' files kept in the Medical record department and the surgical wards. Patients with incomplete data were excluded from the study. Ethical approval to conduct the study was obtained from the WBUCHS/ $\mathrm{BMC}$ joint institutional ethic review committee before the commencement of the study. Data were entered and analyzed using SPSS computer software version 15 . Being a retrospective study, it was not possible to establish exact time period of the onset of the disease, and follow up of the patients was not possible and survival could not be established. By doing prospective study the patients can be properly followed and patient's survival and prognostic factors can be established.

\section{Results}

In this study there were 328 patients with histologically confirmed breast cancer, the mean age at diagnosis was $47.8(+/-13)$ and the median was 46 years. $30.2 \%$ of the patients were in age group of 30 - 40 years, followed by 41-50 years (25.9\%), and age group below 30 years were $21 \%$ and only $17.4 \%$ were above 60 years (Table 1 ). The tumor size ranged from $1 \mathrm{~cm}$ to $18 \mathrm{~cm}$ in diameter with average (mean) of $5.5 \mathrm{~cm}(+/-2.5)$. Majority of the patients $(64 \%)$ were at clinical stage III, and $70.4 \%$ of the patients had lymph node metastasis at the time of diagnosis (Table 1)

Of all patients, 91.5\% (300) had invasive ductal carcinoma, 3\% (10) has Invasive lobular carcinoma and 5.2\% 
Table 1 Patients age profile, clinical stage and lymph Node metastasis at the time of diagnosis

\begin{tabular}{ll}
\hline Age group (years) & $\mathbf{N}(\%)$ \\
\hline Below 30 & $21(6.4)$ \\
$30-40$ & $99(30.2)$ \\
$41-50$ & $85(25.9)$ \\
$51-60$ & $66(20.1)$ \\
Above 60 & $57(17.4)$ \\
Stage at the time of diagnosis & \\
O & $1(0.3)$ \\
I & $14(4.3)$ \\
II & $68(20.7)$ \\
III & $210(64.0)$ \\
IV & $35(10.7)$ \\
Lymph node metastasis & \\
Positive & $231(70.4)$ \\
Negative & $97(29.6)$ \\
\hline Total & 328 \\
\hline
\end{tabular}

(17) had mucinous carcinoma (Figure 1), [Figure 2] and [Figure 3], only one patient had in situ ductal carcinoma. $56.4 \%$ (185) of the patients had histological grade $3,42.1 \%(138)$ grade 2 and $1.5 \%$ (5) grade 1.

Tumor size was significantly associated with rate of lymph node metastasis. Patients with tumors above 6 $\mathrm{cm}$ which was the median size, had high rate of lymph node metastasis compared to patients with tumor below $6 \mathrm{~cm}$ [p $=0.000]$ (Table 2).

Patients below 46 years of age (median age) also had high rate of lymph node metastasis compared to the patients above median age $(\mathrm{p}=0.012)$ (Table 3$)$. Presence of necrosis within the tumor was significantly found in tumors above $6 \mathrm{~cm}[\mathrm{p}=0.000]$ (Table 4) and such tumors were commonly seen in patients below 46

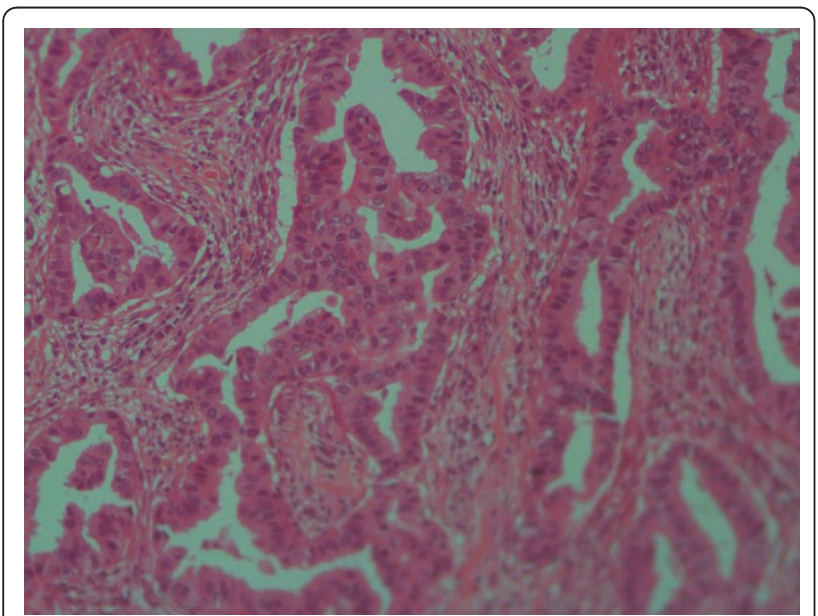

Figure 1 Photomicrograph of Invasive ductal carcinoma of the breast grade $2, \mathrm{H}$ and $\mathrm{E}$ stain $(\times 10)$.

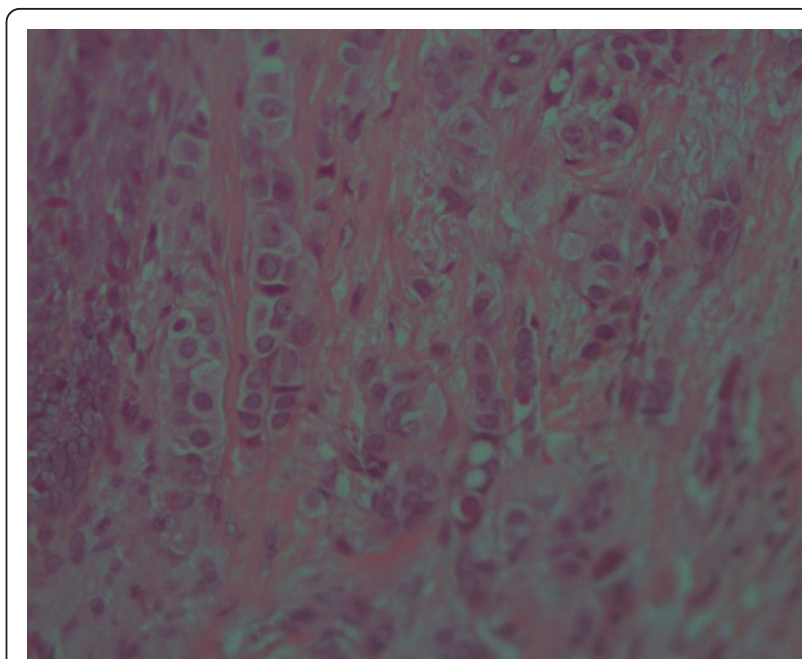

Figure 2 Photomicrograph of Invasive lobular carcinoma of the breast with Typical Indian file pattern of Infiltration, H and E stain $(\times 20)$

years of age $[p=0.012]$ (Table 5), however the presence of necrosis within the tumor was not associated with rate of lymph node metastasis $(\mathrm{p}=0.205)$.

Tumors with low histological grade had low rate of lymph node metastasis compared to high grade tumors, statistical association was not established because only 5 patients (1.6\%) had low grade tumors. All grade one tumors were below $6 \mathrm{~cm}$ in diameter, $58 \%$ of grade two were below $6 \mathrm{~cm}$, and $47.6 \%$ of grade three tumors were below $6 \mathrm{~cm}$, there was a trend of high grade tumors to be of larger size though association could not be established. Ulcerated tumors were commonly seen in grade three tumors, and high grade tumors were also common in patients with less than 46 years of age.

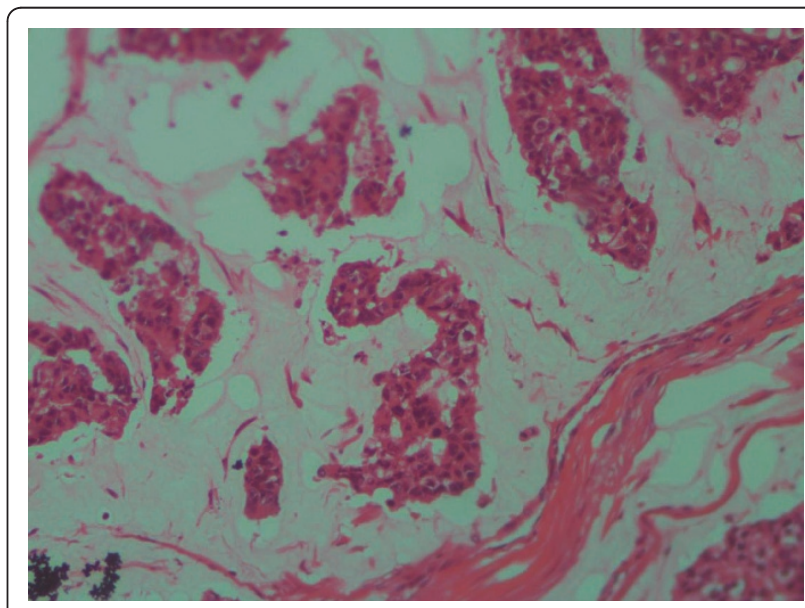

Figure 3 Photomicrograph of mucinous carcinoma of the breast, a cluster of tumor cells in a pool of mucin, $\mathrm{H}$ and $\mathrm{E}$ stain $(\times 20)$ 
Table 2 Tumor size in association with lymph node metastasis

\begin{tabular}{llll}
\hline & $\begin{array}{l}\text { Lymph node positive } \\
\mathbf{N}(\%)\end{array}$ & Total & p-value \\
\hline Tumor size & & & \\
Below $6 \mathbf{c m}$ & $100(57.8)$ & 173 & \\
Above $6 \mathbf{c m}$ & $131(84.5)$ & 155 & 0.000 \\
\hline Total & $\mathbf{2 3 1}$ & $\mathbf{3 2 8}$ & \\
\hline
\end{tabular}

Managements of those patients included mastectomy with axillary lymph node clearance followed by adjuvant hormonal therapy or chemotherapy. A patient with advanced disease, down staging of the tumor was done by radiation followed by surgery. Radiation and chemotherapy was used as palliative care for patients with advanced inoperable disease.

\section{Discussion}

In this study the mean age at diagnosis was 47.8 years, The findings are the same as that seen in Ghana where the mean age at diagnosis was 48 years[19]. Our finding shows that $17.4 \%$ of patients were above 60 years of age, which is the mean age of diagnosis in African American (60.8 years) and in white Americans (62.4 years). It has been reported that the occurrence of breast cancer at young age is associated with a worst prognosis and thus prognosis improves with age, with the best prognosis in patients over 75 years [20]. Similar findings were also seen in Nigeria and Senegal where the mean age at diagnosis was 44.8, with majority of tumors being of high grade, associated with advanced age and lymph node involvement [21]. In our study, 70.4\% had lymph node involvement at the time of diagnosis while $64 \%$ were in stage III (specifically IIB) which is advanced disease. In addition the mean tumor size was larger $(5.5+/-2.5)$ compared to that seen in Nigeria and Senegal $(4.4+/-$ $2.0 \mathrm{~cm}$ ) and histological high grade tumors were $56.4 \%$ which is relatively lower. A study in Uganda which is neighboring country reported the median age at diagnosis to be 45 years with peak age group of 30-39 years [22], This trend is the same as seen in this study. Similarly the study in British black women showed the median age at diagnosis was 46 years as seen in this study, and these patients had also aggressive disease with more

Table 3 Patient age in association with Lymph node metastasis

\begin{tabular}{llll}
\hline Age group (years) & $\begin{array}{l}\text { Lymph node positive } \\
\text { N (\%) }\end{array}$ & Total & p-value \\
\hline Less than/equal 46 & $130(75.5)$ & 172 & \\
Above46 & $101(64.7)$ & 156 & 0.012 \\
\hline Total & 231 & 328 & \\
\hline
\end{tabular}

Table 4 Tumor size in association with necrosis

\begin{tabular}{llll}
\hline Tumor size $\mathbf{( c m )}$ & $\begin{array}{l}\text { Presence of necrosis } \\
\mathbf{N}(\%)\end{array}$ & Total & p-value \\
\hline Below 6 & $59(34)$ & 173 & \\
Above 6 & $86(55.4)$ & 155 & 0.000 \\
\hline Total & 145 & 328 & \\
\hline
\end{tabular}

of histology grade 3, high rate of lymph node metastasis; and majority had triple negative tumors with basal like features[23]. There is a high possibility that our patients might have a lot of triple negative, this is an area which need further investigation. Many studies showed that as the age increases the tumors tends to be less aggressive with low rate of lymph node metastasis, low clinical stage and high levels of ER and PR expression. In younger patients, the tumors tend to be of unfavorable histological features with low receptor status [24]. Another study showed the age of 80 years and above to have more favorable histological features[25], this findings are also seen in our study where patients below 46 years of age had high rate of lymph node metastasis $(\mathrm{p}=0.012)$

In this study the tumor size was significantly associated with presence of necrosis within the tumor and rate of lymph node metastasis. Also large tumors were seen to be of high histological grade although association could not be established due to few numbers of patients in grade one. In this study, large tumor size was associated with younger age (below 46 years), and this could explain the reasons for aggressive disease at younger age. One study showed tumor with necrosis and ER-/PR-were good predictors of metastasis in the lungs[26], and observation from this study showed majority of patients who had metastasis presents with chest symptoms, and with this age profile and histological features there is like hood that majority of our patients are ER-/PR-. Similarly a study in Nigeria showed statistically significant difference in the extent of necrosis in the tumors of postmenopausal and premenopausal patients. Lymph node-positive tumors had more necrosis than lymph node-negative tumors[27]. In this study Necrosis was not associated with lymph node metastasis. Some studies had demonstrated that necrosis is linked to poor prognosis; and necrosis was a feature

Table 5 Tumor size in association with patient's age

\begin{tabular}{lllll}
\hline & $\begin{array}{l}\text { Age less/equal 45 } \\
\text { yrs }\end{array}$ & $\begin{array}{l}\text { Age above 45 } \\
\text { yrs }\end{array}$ & $\begin{array}{r}\text { Total } \\
\text { p- } \\
\text { value }\end{array}$ \\
\hline $\begin{array}{l}\text { Tumor size } \\
(\mathrm{cm})\end{array}$ & & & & \\
Below 6 & 80 & 93 & 173 & \\
Above 6 & 92 & 63 & 155 & 0.012 \\
\hline Total & 172 & 156 & 328 & \\
\hline
\end{tabular}


of tumors possessing an aggressive phenotype (high tumor grade), large size tumor and low estrogen receptor status[28]. In this study necrosis was seen frequently in high grade tumors than low grade tumors, however due to few patients with grade I the statistical difference could not be validated.

Ductal carcinoma was the commonest histological type, which is similar to what is known in literature [29]. In this study $5.2 \%$ (17) were mucinous tumors, this was the second to infiltrating ductal carcinoma, and 10 patients out of 17 were above 46 years of age. The median age of patients with mucinous tumors was 55 years, this is relatively younger compared to other studies, however one study showed this tumors to occur at mean age of 55 years, while another study showed mean age was 53 [30,31]. Both studies showed that Mucinous tumor had tendency to have better prognosis, low recurrence rate and low rate of lymph node metastasis. Lymph node metastasis in mucinous tumor is commonly associated with large tumors as seen in one study (means size of $2.7 \mathrm{~cm}$ ) [32], the high rate of lymph node metastasis seen in our patients could be accounted for by the large tumor size at the time of diagnosis.

\section{Conclusion}

This study showed relatively young age profile of patients with breast cancer in this region, with high rate of lymph node metastasis and advanced clinical stage at the time of diagnosis. This study didn't able to establish exact time onset of the disease and its progress, which needs further investigation. Poor Referral system, natural aggressive biological behavior of tumor may contribute to advanced disease at the time of diagnosis. Raising the public awareness and introduction of screening method can reduce mortality from breast cancer in this community.

\section{Ethical Approval}

The research proposal was presented to joint Bugando Hospital and Weil Bugando University College of Health sciences ethic committee, research and publication where it was approved.

\section{Consent}

This research was retrospective study, histological slides, tissue blocks and patients files were used to get the information, by the time of the research there was no patients available for consent, confidentiality of the patients was maintained, only histology numbers and file numbers were used, this was approved by joint Bugando Hospital and Weil Bugando University College of Health sciences ethic committee, research and publication

\section{Acknowledgements}

Dr Hallgrimur Benediktsson, Department of Pathology and Laboratory Medicine University of Calgary for his contribution in development of this study. Ms Evelyne Konje WBUCHS department of epidemiology for her statistical assistance.

\section{Author details}

${ }^{1}$ Department of Pathology Weill Bugando University College of Health Sciences, Box 1464 Mwanza, (Bugando Street) Postal code +255, Tanzania. ${ }^{2}$ Department of Surgery Weill Bugando University College of Health Sciences, Box 1464 Mwanza, (Bugando Street) Postal code +255, Tanzania. ${ }^{3}$ Department of Anatomy Weill Bugando University College of Health Sciences, Box 1464 Mwanza, (Bugando Street) Postal code +255, Tanzania. ${ }^{4}$ Department of Pathology Bugando Medical Center, Box 1370 Mwanza, (Bugando Street) Postal code +255 , Tanzania.

\section{Authors' contributions}

PR: Main author of the study, involved in design, writing the proposal, data collection, analysis and preparation of the manuscript. PC: Involved in preparation of the study, data collection, clinical staging and preparation of the manuscript. MM: Involved in developing the proposal, data collection and preparation of the manuscript. KJ: Involved in development of proposal, together with main author in review of histological slides and manuscript preparation. All the authors read and approved the final manuscript.

\section{Competing interests}

The authors declare that they have no competing interests.

Received: 7 March 2011 Accepted: 22 June 2011

Published: 22 June 2011

\section{References}

1. Parkin DM, Bray Fl, Devessa SS: Cancer burden in year 2000. The global picture. Eur J Cancer 2001, 37:54-66.

2. William FA, Philip SR, Idan M, Aya M, Ruth MP: Age-Related Crossover in Breast Cancer Incidence Rates Between Black and White Ethnic Groups. JNCl Journal of the National Cancer Institute 2008, 100(24):1804-1814.

3. Parkin DM, Bray Fl, Ferlay J, Pissani P: Global cancer statistics 2002. J Clin Cancer 2002, 55:74-108.

4. Fregene A, Newman LA: Breast cancer in sub-Saharan Africa:how does it relate to a breast cancer in African-American women? Cancer 2005, 103:1540-1550.

5. Amir H, Parkin DM: A comparative study of carcinoma of the breast in an African population. East Afr Med J 1994, 71(4):215-218.

6. Amir H, Aziz MR, Makwaya CK, Jessani S: TNM classification and breast cancer in an African population: a descriptive study. Cent Afr J Med 1997 43(12):357-359.

7. Mimi CY, Ronald KR, Yu-Tang G, Brian EH: Risk Factors for Breast Cancer in Chinese Women in Shangai. Cancer research 1998, 48:1949-1953.

8. Amir H, Kwesigabo G, Aziz MR, Kitinya JN: Breast cancer and conservative surgery in sub Saharan Africa. East Afr Med J 1996, 73(2):81-82.

9. Ikpatt OF, Kuopio T, Ndoma-Egba R, Collan Y: Breast cancer in Nigeria and Finland: epidemiological, clinical and histological comparison. Anticancer Res 2002, 22(5):3005-3015.

10. Awadelkarim KD, Arrizi C, Elamin EOM, et al: Pathological, clinical and prognostic characteristics of breast cancer in Central Sudan versus Northern Italy: implications for breast cancer in Africa. Histopathology 2008, 52(445-456)

11. Gondos A, Brenner $H$, Wabinga $H$, Parkin DM: Cancer survival in Kampala, Uganda. Br J Cancer 2005, 92:1808-1812.

12. Maureen C, Helena RC, Kirby IB, Harold JW: Younger Women with Breast Carcinoma Have a Poorer Prognosis than Older Women. Cancer 1996, 77:97-103.

13. Henson DE, Ries L, Freedman LS, Carriaga M: Relationship Among Outcome, Stage of Disease, and Histologic Grade for 22,616 Casesof Breast Cancer. The Basis for a Prognostic Index Cancer 1991, 68(10):2142-2149.

14. Elston CW, Ellis O: Pathological prognostic factors in breast cancer. The value of histological grade in breast cancer: Experience from a large study with long-term follow-up. Histopathology 1991, 19:403-410. 
15. Elston CW: Classification and grading of invasive breast carcinoma. Verh Dtsch Ges Pathol 2005, 89:35-44.

16. Robbins P, de Klerk NPinder, Dawkins H: Histological Grading of Breast Carcinomas:A Study of Interobserver Agreement. Human Patholog 1995, 26(8):873-879.

17. Rafael EJ, Tracy W, Daniel WV: Centrally Necrotizing Carcinomas of the Breast. A Distinct Histologic Subtype with Aggressive Clinical Behavior. The American Journal of Surgical Pathology 2001, 25(3):331-337.

18. Ikpatt O, Ndoma-Egba R, Collan Y: Prognostic value of necrosis in Nigerian breast cancer. Adv Clin Path 2002, 6(1):31-37.

19. Stark A, Kleer CG, Martin I, et al: African ancestry and higher prevalence of triple-negative breast cancer: findings from an international study. Cancer 2010, 116(21):4926-4932.

20. Zavagno G, Meggiolaro F, Pluchinotta A, et al: Influence of age and menopausal status on pathologic and biologic features of breast cancer. Breast 2000, 9(6):320-328.

21. Huo D, Adebamowo CA, Ogundiran TO, et al: Population differences in breast cancer: survey in indigenous African women reveals overrepresentation of triple-negative breast cancer. J Clin Oncol 2009, 27(27):4515-4521.

22. Galukande M, Jombwe J, Fualal J, et al: Cancer of the breast: 5-year survival in a tertiary hospital in Uganda. Br J Cancer 2008, 99(1):63-67.

23. Bowen RL, Duffy SW, Ryan DA, et al: Early onset of breast cancer in a group of British black women. Br J Cancer 2008, 98(2):277-281.

24. Dobi $A$, Kelemen $G$, Kaizer $L$, et al: Breast Cancer under 40 Years of Age: Increasing Number and Worse Prognosis. Pathol Oncol 2011, 17(2):425-428.

25. Chatzidaki P, Mellos C, Briese V, Mylonas I: Does primary breast cancer in older women $(>/=80$ years) have unfavorable histological characteristics? Arch Gynecol Obstet 2010, PMID 20949358.

26. Hasebe T, Imoto S, Yokose T, Ishii G, Iwasaki M, Wada N: Histopathologic factors significantly associated with initial organ-specific metastasis by invasive ductal carcinoma of the breast: a prospective study. Hum Pathol 2008, 39(5):681-693.

27. Ikpatt O, Ndoma-Egba R, Collan Y: Prognostic value of necrosis in Nigerian breast cancer. Adv Clin Path 2002, 6(1):31-37.

28. Leek RD, Landers RJ, Harris AL, Lewis CE: Necrosis correlates with high vascular density and focal macrophage infiltration in invasive carcinoma of the breast. Br J Cancer 1999, 79(5-6):991-995.

29. Sheikh MK, Khan FA, Imran Abdul Khalid IK, Kumar G: Age specific histologic types of carcinoma breast in Malaysians. I Coll Physicians Surg Pak 2009, 19(3):201-202.

30. Peng L, Sun Q, Liang ZY, Zhou YD, Mao F, Guan JH: Pure mucinous carcinoma of the breast: a clinicopathologic analysis with 56 patients. Chin Med Sci J 25(2):115-118.

31. Hanagiri T, Ono K, Baba T, et al: Clinicopathologic characteristics of mucinous carcinoma of the breast. Int Surg 2010, 95(2):126-129.

32. Barkley CR, Ligibel JA, Wong JS, et al: Mucinous breast carcinoma: a large contemporary series. Am J Surg 2008, 196(4):549-551.

doi:10.1186/1756-0500-4-214

Cite this article as: Rambau et al:: Pathological features of Breast Cancer seen in Northwestern Tanzania: a nine years retrospective study. BMC

Research Notes 2011 4:214.

\section{Submit your next manuscript to BioMed Central and take full advantage of:}

- Convenient online submission

- Thorough peer review

- No space constraints or color figure charges

- Immediate publication on acceptance

- Inclusion in PubMed, CAS, Scopus and Google Scholar

- Research which is freely available for redistribution 